MECHANICAL PROPERTIES OF MICROCAST-Xं ALLOY 718

FINE GRAIN INVESTMENT CASTINGS

G. K. Bouse and M. R. Behrendt

Howmet Corporation

Technical Center

Whitehall, MI 49461

\title{
INTRODUCTION
}

Microcast- $X^{\circledR}$ (abbreviated $M X^{\circledR}$ ) Alloy 718 castings are finding numerous uses as structural components in jet engines. Applications include pressure housings and other external components that encase the compressor and turbine sections. The size of these parts approach $1.5 \mathrm{~m}$ ( 60 inches) in diameter. These single or clam shell structural castings are replacing fabricated assemblies previously made by welding many individual cast and wrought components.

The patented MX process [1] provides an advancement over conventional investment cast components in two important ways. First, the grain structure in the MX casting is non-dendritic. The grains produced by the MX process more closely resemble the grains in a forging. This grain size is on the order of ASTM 3 or finer which provides many advantages including better tensile properties, fatigue properties, weldability, and inspectability. Second, the absence of essentially all columnar grains leads to more metallurgical uniformity regardless of component size or shape. Thus, designers can predict properties with more confidence. This process is compatible with a variety of superalloys, especially Mar-M-247 which is also being used for structural applications.

The MX casting process is not without a drawback - there are some limitations on filling thin sections. Because of the lower pour temperatures used, the fluidity of the liquid metal is less than it is with conventional casting. MX produced castings also require the use of Hot Isostatic Pressing (HIP), because of the limited feeding characteristics. However, HIP is being used to upgrade cast Alloy 718 for many aerospace applications regardless of casting technique.

This paper characterizes MX cast Alloy 718 relative to tensile properties (cryogenic to $650 \mathrm{C}(1200 \mathrm{~F})$ ), stress rupture properties, low cycle fatigue $(480 \& 540 \mathrm{C}(900 \& 1000 \mathrm{~F}))$, and high cycle fatigue (room temperature and $480 \mathrm{C}$ (900F)). Because MX material is approaching the mechanical properties of a typical forging, AMS 5662 material was used for comparison purposes. In addition, the MX castings were compared to state-of-the-art conventional cast + HIP material.

Superalloy 718 - Metallurgy and Applications

Edited by E.A. Loria

The Minerals, Metals \& Materials Socicty, 1989 


\section{MATERIALS AND PROCESSING}

All investment cast test specimens were made from molds containing sixteen 16 $\mathrm{mm}$ ( $5 / 8$ inch) diameter bars, $15 \mathrm{~cm}$ ( 6 inches) long, being fed from the top only. One or two test specimens were machined from each bar. The molds were cast at Howmet foundries in LaPorte, IN, and Dover, NJ under typical production conditions. This mold was selected so that mechanical properties derived from them would simulate the mechanical properties in slabs, or flanges of actual hardware having similar thickness.

The MX material was produced by pouring metal with a range of superheat conditions that provided the desired fine grain size. All of the MX metal came from heat "A" having a composition listed in Table I. After casting, the bars were HIP'd at $1120 \mathrm{C} / 103 \mathrm{MPa} / 3 \mathrm{hrs}(2050 \mathrm{~F} / 15 \mathrm{ksi} / 3 \mathrm{hrs})$ and given the AMS 5383 heat treatment which corresponds to: $1095 \mathrm{C}(2000 \mathrm{~F}) / 1 \mathrm{hr}$ and gas fan cool (GFC); 955C (1750F)/1 hr + GFC; standard age cycle - 720C (1325F)/ $8 \mathrm{hrs}$, cool 55C (100F)/hour to $620 \mathrm{C}$ (1150F) and hold an additional eight hours. The microstructure of the MX material is shown in Figure 1a; the grain size was typically within ASTM $3-4(0.07-0.11 \mathrm{~mm}, 0.003-0.004$ inches). It should be noted that this heat treatment was designed to minimize grain growth. Some Laves' phase was present in the microstructure.

Two groups representing conventional cast + HIP material were also used in the study. One group utilized metal from heat "A" except that it was poured with at least $85 \mathrm{C}$ (150F) superheat, but otherwise HIP'd and heat treated similarly. The other group came from heat "B" using a higher superheat and a heat treatment that eliminated most of the Laves' phase. That heat treatment consisted of: HIP at $1165 \mathrm{C} / 103 \mathrm{MPa} / 4 \mathrm{hrs}(2125 \mathrm{~F} / 15 \mathrm{ksi} / 4 \mathrm{hrs}) ; 1135 \mathrm{C}$ (2075F)/10 hrs; 955C (1750F)/1 hr; standard age cycle. Typical microstructures of the conventional cast + HIP materials after all processing are shown in Figures $1 \mathrm{~b} \& 1 \mathrm{c}$. The grains in the conventional cast + HIP material were a mixture of equiaxed and columnar dendritic structures, having an average dimension of $2-6 \mathrm{~mm}(1 / 16-1 / 4$ inch.).

The wrought material was procured as a hot finished $19 \mathrm{~mm}(3 / 4$ inch) diameter bar, meeting AMS 5662 (excepting final heat treatment). A grain size of ASTM 4-5 was produced by solutioning at 1040C (1900F)/1 hour + GFC; 955C (1750F)/1 hour + GFC; standard age cycle. This material had a grain size diameter in the range of ASTM 4-5 (0.06-0.09 $\mathrm{mm}, 0.002-0.004 \mathrm{inch})$, as shown in Figure $1 d$.

\section{MECHANICAL TESTING PROCEDURES}

The mechanical test specimens used in this study are illustrated in Figure 2. All specimens were machined using conventional practice.

Tensile Testing. Room temperature tensile tests were conducted according to the requirements of ASTM E8. Extensometers were used to measure the $0.2 \%$ offset yield strength (YS) at a strain controlled rate of $0.005 /$ minute, after which a crosshead speed of $1.27 \mathrm{~mm} / \mathrm{minute}(0.05 \mathrm{inch} / \mathrm{min}$.) was maintained

TABLE I - COMPOSITIONS OF ALLOY 718 (WEIGHT PERCENT)

\begin{tabular}{|c|c|c|c|c|c|c|c|c|c|c|}
\hline & $C$ & $\underline{\mathrm{Si}}$ & $\mathrm{Mn}$ & $\mathrm{Cr}$ & $\mathrm{Fe}$ & $\mathrm{Cb}$ & Mo & $\underline{\mathrm{T} i}$ & Al & $\mathrm{Ni}$ \\
\hline Heat "A" & 0.05 & $<.05$ & $<.05$ & 19.3 & $\mathrm{Bal}$ & 4.9 & 3.1 & 0.93 & 0.56 & 51.1 \\
\hline Heat "B" & 0.05 & 0.05 & 0.06 & 17.9 & $\mathrm{Bal}$ & 5.0 & 3.0 & 0.99 & 0 & 53.5 \\
\hline rought Mat'l. & 0.05 & 0.22 & 0.18 & 17.9 & 18.84 & 5.1 & 3.0 & 1.12 & 0.63 & $\mathrm{Bal}$ \\
\hline
\end{tabular}


until failure. Blevated temperature tests were conducted as described in ASTM E21. The cryogenic tests were conducted in $\mathrm{LN}_{2}$ at a commercial testing source. For the cast materials, 4-8 tests were conducted per condition (superheat, temperature), compared to 2-4 tests per condition for the wrought material.

Stress Rupture Testing. The stress rupture tests vere conducted between $540 \mathrm{C}$ (1000F) and 705C (1300F), according to ASTM E139.

Low Cycle Fatigue (LCF) Testing. LCF testing was performed at 480C (900F) and $540 \mathrm{C}(1000 \mathrm{~F})$ in laboratory air, according to ASTM E606. The specimens were heated with induction coils, and temperatures in the gauge section were maintained within $3 \mathrm{C}(5 \mathrm{~F})$ of the aim temperature. The gauge section of the test bars was coated with high temperature paint to provide a constant

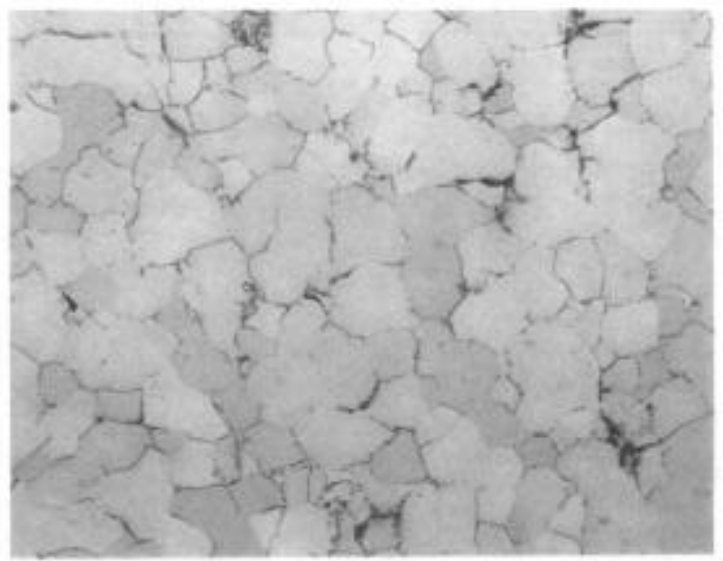

(a) Microcast-X Alloy 718, ASTM 3-4

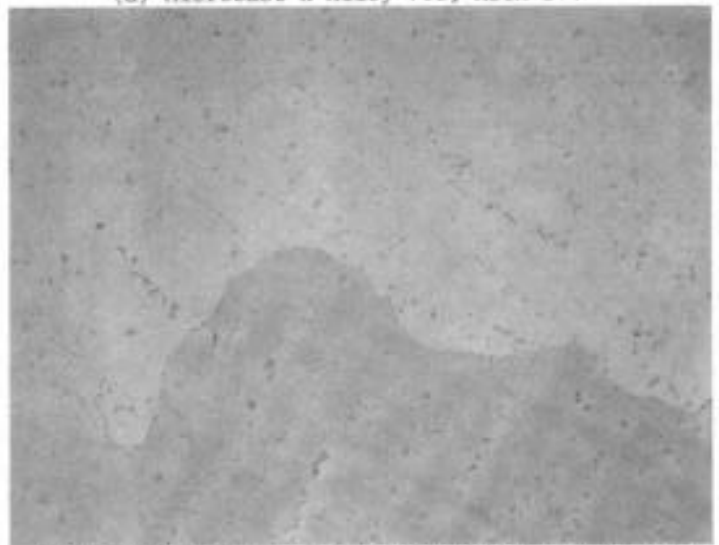

(c) Conventional Cast + $1165 \mathrm{C}(2125 \%)$ HIP Alloy 718

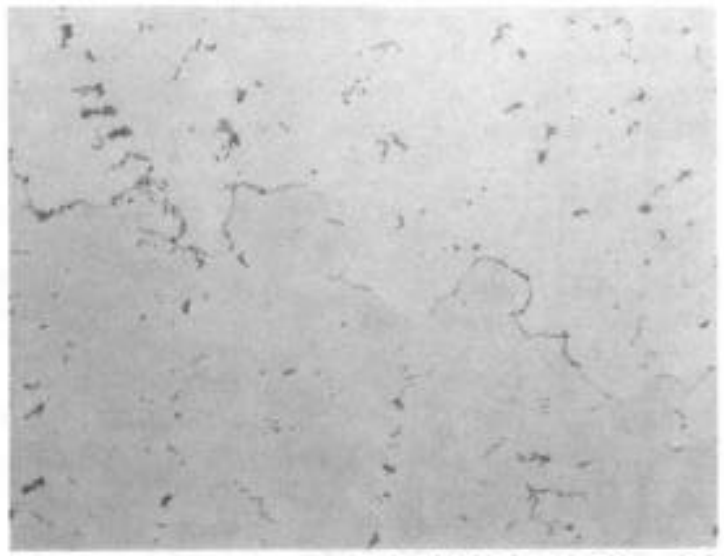

(b) Conventional Cast $+1120 \mathrm{C}$ (2050F) HTP A11oy 718

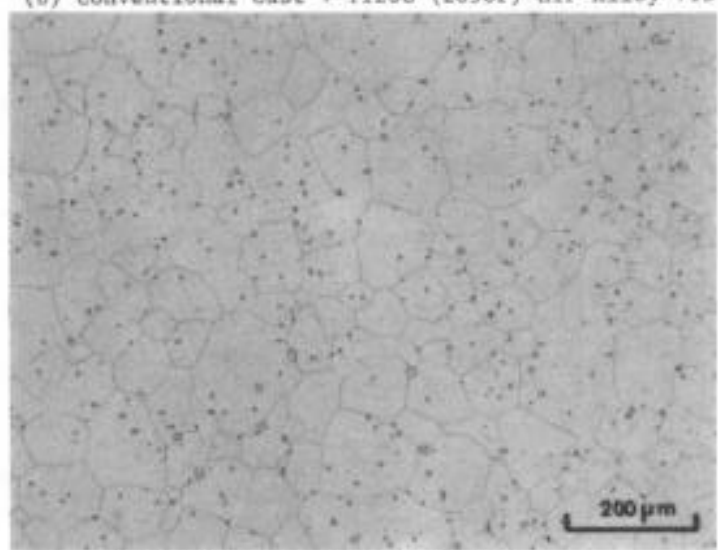

(d) Wrought Atloy 718 , ASTM $4-5$

Figure 1. Microstructures of the Alloy 718 materials used in this study; a) Microcast-X, b) Conventional Cast + 1120C (2050F) HIP, c) Conventional Cast $+1165 \mathrm{C}(2125 \mathrm{~F})$ HIP, and d) wrought mat'1.

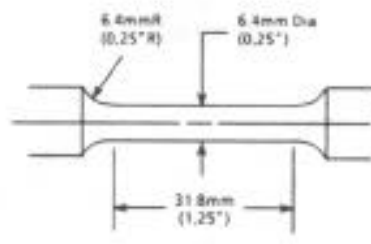

Tensile and Stress tupture Bar

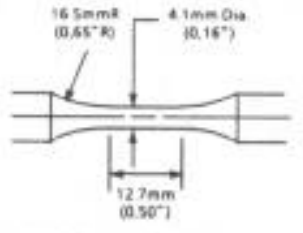

High Cycie Fatigue Bar

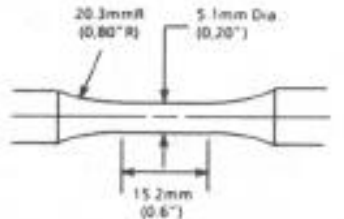

Low Cycle fatigue Bar

Figure 2. Tensile, stress rupture, HCF, and LCF test specimens. Dimensions are in millimeters and (inches). 
emissivity of 0.86 for the infrared pyrometer, which was used to control the test temperature. A second optical pyrometer was also used to periodically verify the temperature.

All tests were conducted in strain control using a closed loop, servohydraulic load frame. A frequency of $20 \mathrm{cpm}(.33 \mathrm{~Hz})$, and a triangular wave form were used to minimize creep interactions. The testing was done with an " $A$ " ratio of $+1(R$ ratio $=0$ ) with the minimum strain at zero. Cycling was continuously monitored to detect a $5 \%$ drop in load which was interpreted as the initiation of cracking. Stress-strain hysteresis curves were taken at a cycle count of $1,50,500$, doubling every cycle thereafter. Testing was continued until specimen failure or a cycle count of 100,000 was reached.

High Cycle Patigue (HCF) Testing. HCF testing was performed at room temperature and 480C (900F) in laboratory air, according to ASTM E466. The elevated temperature specimens were heated as described above. All tests were conducted in load control using a closed loop, servo-hydraulic load frame. A sine wave form with an $R$ ratio $=-1$ (mean stress of zero) was used in all cases; most of the testing was conducted at a frequency of $30 \mathrm{~Hz}(1800$ cpm). Testing was terminated at specimen failure or a cycle count of ten million.

\section{RESULTS and DISCUSSION}

\section{Tensile Tests}

Room temperature tensile data for MX Alloy 718 are shown in Figure 3, along with the wrought and conventional cast + HIP materials. Much of the scatter for MX tensile data is due to the presence of Laves' phase. The test bars with greatest strength and ductility had a minimal amount of Laves' phase. This was determined by sectioning many of the failed test bars and visually noting them at $10 \mathrm{X}$ to contain either "minimal" or "much" Laves' phase. Laves' phase probably varied due to slightly different solidification conditions within the mold depending upon the location of the test bar, the spacing between bars, thickness of the shell, and mold wrap. Such variation would also be typical of a production casting of which this mold type was designed to represent.

A tensile bar with much Laves' phase is shown in Figure 4. Fracture occurred both within the Laves' phase, and at the Laves'/matrix interface. Laves' phase is generally understood to compromise the mechanical properties of cast Alloy 718 , because it removes $\mathrm{Cb}$ from the matrix and decreases the strengthening potential of $\gamma^{\prime \prime}$ which also contains Cb. Laves' is an A, B type intermetallic [2] which is brittle, thereby leading to reduced ductility as well. Fortunately, Laves' can be controlled by heat treatment which is explained elsewhere [3].

Laves' phase was only partially solutioned with the 1120C (2050F) HIP cycle which was chosen to avoid grain growth. For the MX material used in this study grain growth was observed at $1130 \mathrm{C}$ (2070F). While higher tensile properties and less scatter could probably be achieved with complete Laves' solutioning, there may be a trade-off with fatigue properties due to the larger grain size resulting from the higher solutioning temperatures.

Despite the presence of Laves' phase, the MX material had favorable properties when compared to the wrought material or conventional cast + HIP materials as shown in Table II.

Cryogenic and elevated temperature tensile tests. The average tensile values were plotted with a spline curve fit versus temperature; these results are illustrated in Figure 5. The data show that MX material has $~ 90 \%$ of the wrought UTS and YS over the entire temperature range. The MX UTS and YS are 

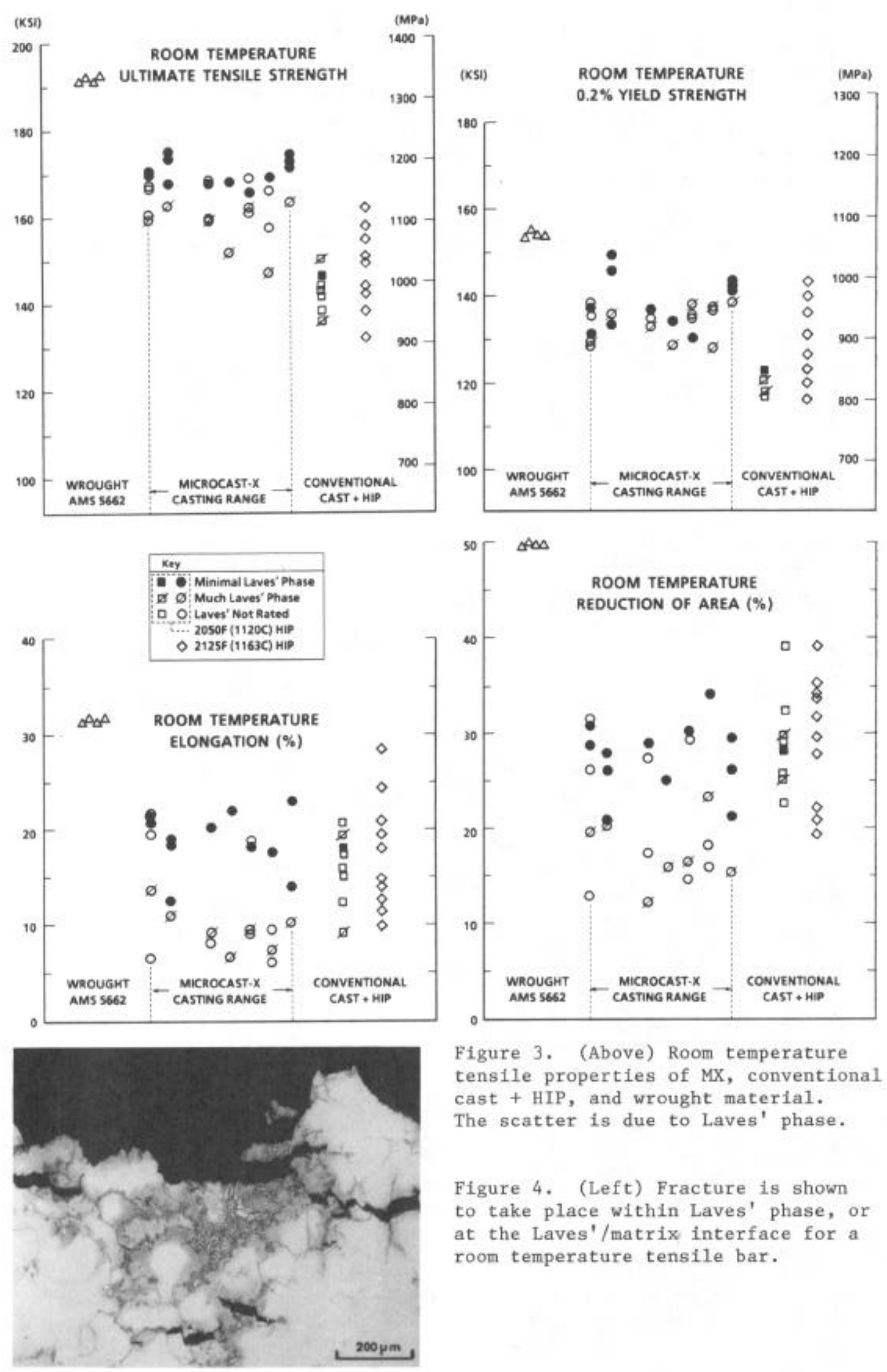

Figure 3. (Above) Room temperature tensile properties of MX, conventional cast + HIP, and wrought material.

The scatter is due to Laves' phase.

Figure 4. (Left) Fracture is shown to take place within Laves' phase, or at the Laves'/matrix interface for a roon temperature tensile bar. 
much better than the strength of either conventional cast + HIP materials, especially at the cryogenic temperature. The EL of all cast materials had about half the EL of the wrought material at room temperature and below. However, at 316C (600F) and above, MX Alloy 718 became the superior cast material having $\sim 85 \%$ of the wrought EL. The RA for all of the cast materials had about half of the wrought RA at the lower temperatures. At the higher temperatures the RA of the cast materials increased until they exceeded the RA for wrought material at $650 \mathrm{C}(1200 \mathrm{~F})$.

TABLE II - COMPARISON OF MX ALLOY 718 ROOM TEMPERATURE TENSILE PROPERTIES TO WROUGHT AND CONVENTIONAL CAST + HIP MATERIALS

\begin{tabular}{|c|c|c|c|c|c|c|c|c|}
\hline ALLOY 718 TYPE & $\begin{array}{c}\text { UTS } \\
\text { MPa } \\
\text { (KSI) } \\
\end{array}$ & $\begin{array}{l}\% \text { OF } \\
\text { WROUGHT }\end{array}$ & $\begin{array}{l}\text { YS } \\
\text { MPa } \\
\text { (KSI) }\end{array}$ & $\begin{array}{l}\% \text { OF } \\
\text { WROUGHT }\end{array}$ & \%EL & $\begin{array}{l}\% \text { OF } \\
\text { WROUGHT }\end{array}$ & \% RA & $\begin{array}{l}\% \text { OF } \\
\text { WROUGHT }\end{array}$ \\
\hline Wrought & $\begin{array}{l}1317 \\
(191.1)\end{array}$ & $100 \%$ & $\begin{array}{l}1056 \\
(153.2)\end{array}$ & $100 \%$ & 31.8 & $100 \%$ & 48.1 & $100 \%$ \\
\hline Microcast-X & $\begin{array}{l}1146 \\
(166.3)\end{array}$ & $87 \%$ & $\begin{array}{l}942 \\
(136.7)\end{array}$ & $89 \%$ & 15.1 & $47 \%$ & 23.1 & $48 \%$ \\
\hline $\begin{array}{l}\text { Conventional Cast } \\
+1120 \mathrm{C}(2050 \mathrm{~F}) \text { HIP }\end{array}$ & $\begin{array}{l}970 \\
(140.7)\end{array}$ & $74 \%$ & $\begin{array}{l}831 \\
(120.5)\end{array}$ & $79 \%$ & 16.3 & $51 \%$ & 28.9 & $60 \%$ \\
\hline $\begin{array}{l}\text { Conventional Cast } \\
+1163 \mathrm{C}(2125 \mathrm{~F}) \text { HIP }\end{array}$ & $\begin{array}{l}1017 \\
(147.5)\end{array}$ & $77 \%$ & $\begin{array}{l}891 \\
(129.3)\end{array}$ & $84 \%$ & 16.7 & $53 \%$ & 31.2 & $65 \%$ \\
\hline
\end{tabular}
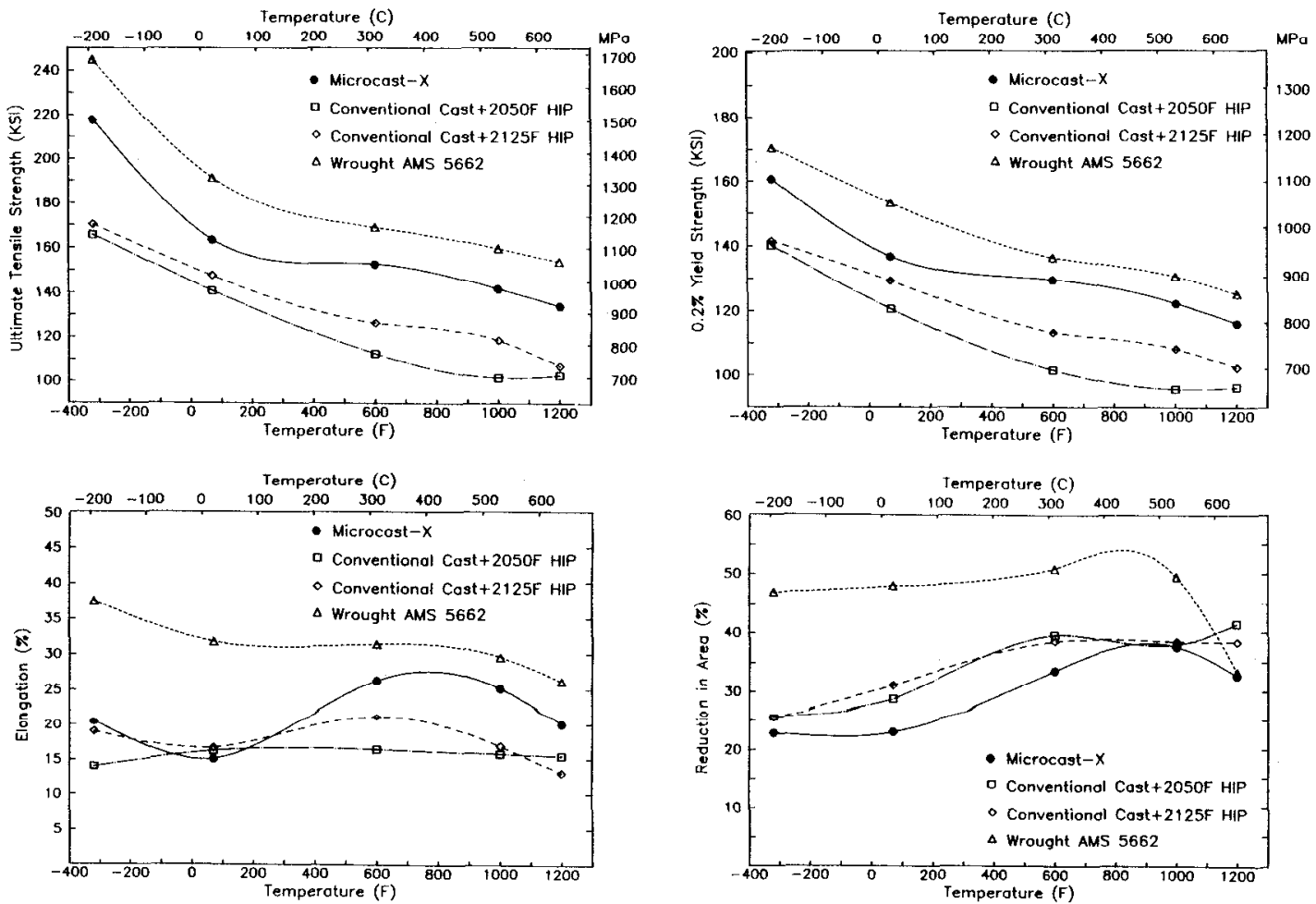

Figure 5. Mean values for tensile properties of Microcast-X, conventional cast + HIP, and wrought Alloy 718 are plotted versus temperature. 


\section{Stress Rupture Testing}

The stress rupture data is plotted in Figure 6 using a Larson-Miller equation. Taking into account that average life was 350 hours, at a stress of $792 \mathrm{MPa}$ (115 ksi), the MX material was found to have a $28 \mathrm{C}$ (50F) advantage over conventional cast $+1120 \mathrm{C}$ (2050F) HIP material. The wrought material has only a $14 \mathrm{C}$ (25F) advantage over the MX material. This increase in temperature potential of the $\mathrm{MX}$ material is substantial as the conventional cast $+1120 \mathrm{C}$ (2050F) HIP data represents premium material now being used in production.

The cross-over for stress rupture life, or equicohesive temperature (ECT), was calculated to occur at $712 \mathrm{C}(1314 \mathrm{~F})$. If used above this temperature the conventional cast + HIP material would be advantageous, due to decreasing creep rates associated with the larger grain size. Thus, above the ECT, the MX material has no advantage over conventional cast + HIP material.

\section{Low Cycle Fatigue (LCF)}

LCF tests at $480 \mathrm{C}(900 \mathrm{~F})$ were plotted using the total percent strain $\left(\% \varepsilon_{f}\right)$ versus cycles to specimen separation $\left(\mathrm{N}_{f}\right)$ in Figure 7 . A linear regression analysis was performed on the logarithm of both $N_{f}$ and $\% \varepsilon_{t}$ and fit to equation (1). Equation ( 1 ) is then solved for $\% \varepsilon_{t}$ to obtain the strain and cycle count relationship of equation (2), according to ASTM E739.

$$
\begin{aligned}
\log \left(\varepsilon_{t}\right) & =A+B \log \left(N_{f}\right) \\
\varepsilon_{t} & =10^{A} \times N_{f}^{B}
\end{aligned}
$$

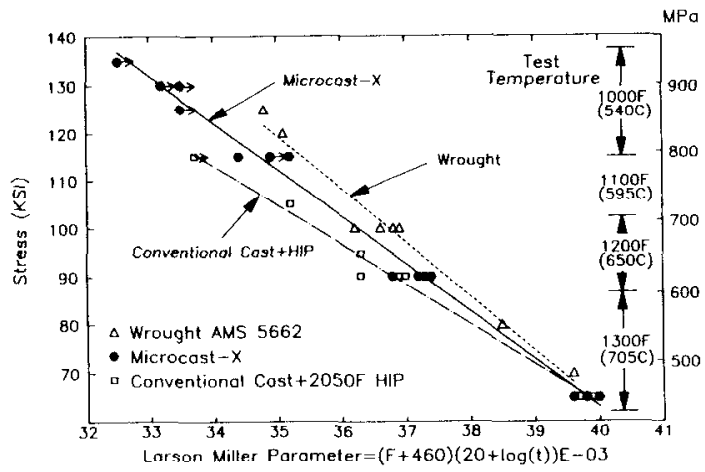

Figure 6. (Left) Stress rupture life of Microcast-X, conventional cast + HIP, and wrought materials.

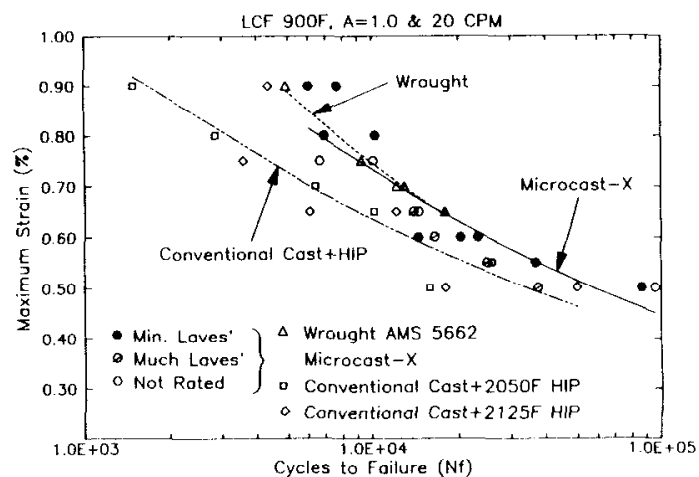

Figure 7. MX Alloy 718 offers a $2 \mathrm{X}$ LCF life advantage over conventional cast + HIP materials. MX material has nearly equivalent LCF life when compared to wrought material.

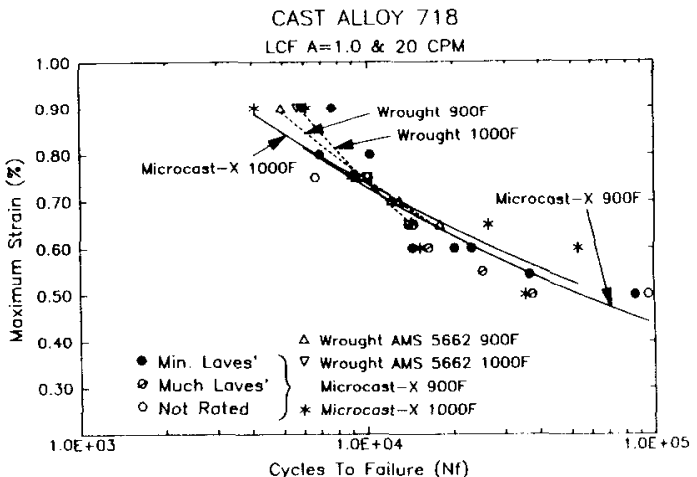

Figure 8. There is little difference in LCF life at 480-540C (900-1000F) for MX or wrought Alloy 718 . 
The two sets of conventional cast + HIP data were plotted separately and the mean line from each set was practically identical. Keep in mind the $1165 \mathrm{C}$ (2125F) HIP material had greater EL, less Laves' phase, and greater strength than the 1120C (2050F) HIP material. The grain sizes for the two materials were both very large. These considerations are important when considering how tensile strength and ductility influence fatigue strength. Generally, a higher UTS will improve the elastic (low $\varepsilon$ ) part of the LCF curve, and higher ductility (interpreted as EL) will improve the plastic (high $\varepsilon$ ) part of the curve [4]. It is possible that the differences in UTS and EL between the two conventional cast + HIP materials were not different enough to produce different LCF characteristics.

However, when the MX data was added to Figure 7 , it had roughly equivalent increases in UTS and EL (at temperature) over the conventional cast $+1165 \mathrm{C}$ (2125F) HIP material, as did the $1165 \mathrm{C}$ (2125F) HIP material over the $1120 \mathrm{C}$ (2040F) HIP material. In this case, the LCF life increased by a factor of two! It is suggested the reason for improved fatigue life of MX material was the fine grain size. By examination of Figure 5, it was surmised that fine grain size was the only reason for the improved UTS and EL, by comparing the UTS and EL of MX material to the UTS and EL of conventional cast $+1120 \mathrm{C}$ (2050F) HIP material (at 480C (900F)). It was further surmised the large grain size of conventional cast + HIP materials is what limits it's LCF life. Thus, the presence of Laves' in conventional castings is of little consequence concerning LCF life. This is probably one reason why it has been difficult to unambiguously prove the presence of Laves' is detrimental in a conventional casting.

Both MX and conventional cast materials appear to have equivalent scatter. The scatter for the cast materials is about double the scatter for the wrought material. Examination of the fracture surfaces by SEM indicates no apparent influence of inclusions for any of the test bars; etching of the test bar surfaces, especially the MX material, also shows that random large grains were not an issue. For the MX material, about half of the scatter is believed to be the normal scatter encountered in LCF testing (due to minor microstructural variations, test bar machining practice, machine calibration, etc.). The other half of the scatter is due to Laves' phase. In Figure 7, the MX bars with "much" Laves' phase all fall below the mean line. By eliminating Laves', the scatter of MX material (which has a grain size of ASTM 3-4) would be expected to be more like the scatter in wrought material (which has a grain size of ASTM 4-5).

Thus, in MX material the Laves' phase supposedly has a direct influence on LCF life; whereas with conventional cast material, it does not. one reason to explain this difference may be the Laves' phase distribution. In MX material, Laves' is primarily on the grain boundaries. In conventional cast + HIP material, Laves' is found primarily within the grains, but is also found on grain boundaries. By comparing crack propagation modes, this difference will become more evident, which is an area of current study.

As explained earlier, the wrought material is slightly superior to the MX material. Although the mean line for wrought appears as though it would fall below the MX line if extrapolated, it is probable that it would not if the number of data points for the wrought alloy equaled the number for MX or conventional cast + HIP. It is doubtful that MX cast material could exceed the fatigue strength of wrought material given similar grain sizes and complete absence of Laves' phase. The wrought material also contains additional strengthening mechanisms such as stored residual energy (that not used-up during recrystallization) and texture, both of which can contribute towards improved fracture resistance.

LCF test results at $540 \mathrm{C}$ (1000F) were compared to the $480 \mathrm{C}$ (900F) data in Figure 8. The increase in test temperature had little effect on the fatigue performance for either alloy type tested. Once again, the wrought material fatigue life has a small advantage over MX Alloy 718. 


\section{High Cycle Patigue (BCF)}

HCF tests were also conducted at $480 \mathrm{C}(900 \mathrm{~F})$. Since the LCF behavior of the two conventional cast + HIP materials were similar, it was decided to only test the wrought, and cast material HIP'd at $1120 \mathrm{C}$ (2050F). This data was analyzed similar to the LCF tests except that maximum stresses were used instead of $\% \varepsilon_{\mathrm{t}}$. The HCF data is plotted in Figure 9.

The MX material has a 5-14X advantage over the conventional cast $+1120 \mathrm{C}$ (2050F) HIP material. The scatter for the MX material was again comparable to the conventional cast $+1120 \mathrm{C}$ (2050F) HIP data. Although not as many bars were evaluated for amounts of Laves' phase, half of the scatter is presumably due to Laves' phase. SEM examination of the fracture surfaces showed no inclusions and grain etch of the test bar surfaces showed a uniform grain size. The one MX data point at $413 \mathrm{MPa}$ (60 ksi) just above the mean line had a grain on the fracture surface $-3 x$ larger than usual, as shown in Figure 10. This grain was fairly obvious and was found using a binocular microscope. Thus, the existence of a single large grain did not cause early failure.

The room temperature $\mathrm{BCF}$ tests shown in Figure 11 have $70 \mathrm{MPa}$ (10 ksi) greater fatigue strength than the $480 \mathrm{C}$ ( $900 \mathrm{~F}$ ) tests. Bven though the room temperature tests were conducted at $60 \mathrm{~Hz}$, the effect of frequency at room temperature is considered minimal.

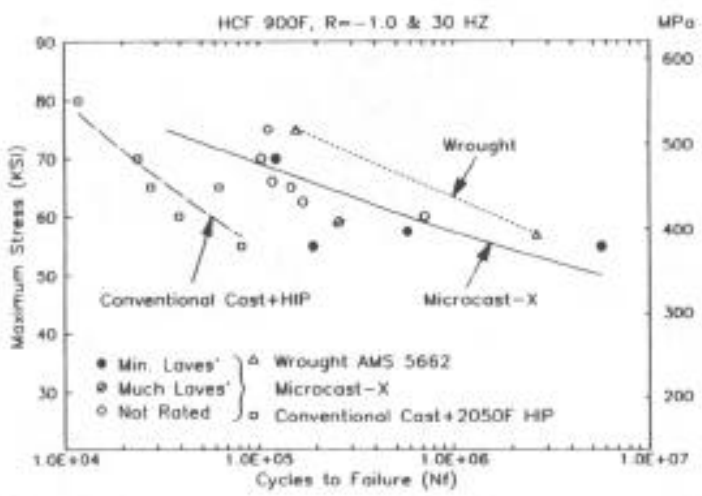

Figure 9. MX Alloy 718 offers a 5-14X HCF life advantage over conventiona 1 cast + HIP material at $480 \mathrm{C}$ ( $900 \mathrm{~F}$ ), while wrought Alloy 718 offers a $3-5 \mathrm{X}$ advantage over cast MX A11oy 718 .

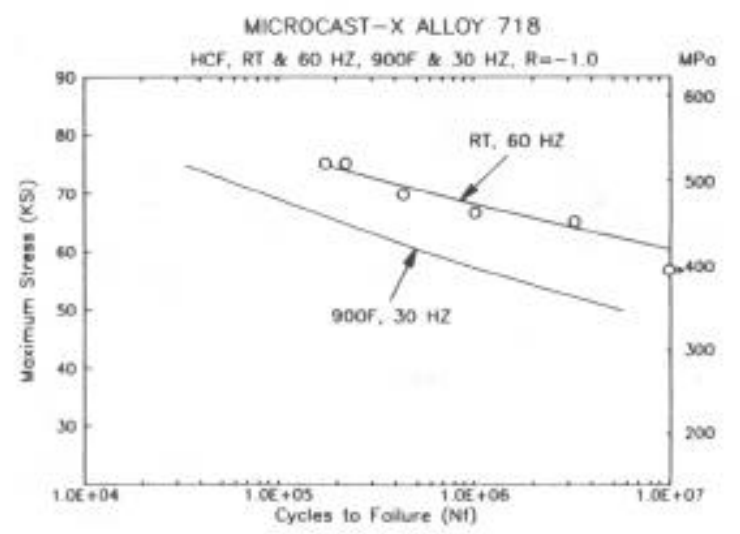

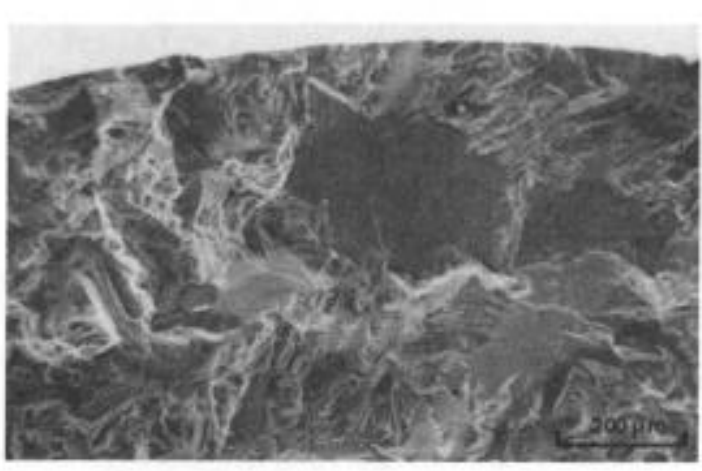

Figure 10. A random large grain ( $3 \mathrm{X}$ normal size) did not reduce HCF 11 fe of MX Alloy 718 at 413 $\mathrm{MPa}(60 \mathrm{ksi})$ and $480 \mathrm{C}(900 \mathrm{~F})$.

Figure 11. (Left) HCF life of MX Alloy 718 at room temperature and $480 \mathrm{C}$ (900F). 


\section{SUMMARY}

1. The ultimate tensile and yield strength of MX Alloy 718 is within $\sim 90 \%$ of the wrought AMS 5662 material over a wide range of temperatures. The tensile ductility of MX Alloy 718 is about half that of the wrought material, but is comparable to conventional cast + HIP materials.

2. The scatter in MX tensile and fatigue data was shown to be due to the presence of Laves' phase (which can be removed by heat treatment). The effect of Laves' phase was more pronounced as the grain size was reduced.

3. MX processed Alloy 718 improves the stress rupture capability over conventional cast + HIP material by 28C (50F). Wrought Alloy 718 offers only a $14 \mathrm{C}(25 \mathrm{~F})$ advantage over cast MX Alloy 718 material.

4. MX Alloy 718 offers a $2 X$ low cycle fatigue life improvement over conventional cast + HIP materials. The LCF life of the cast MX Alloy 718 was nearly equivalent to the wrought material.

5. MX Alloy 718 offers a $5-14 \mathrm{X}$ high cycle fatigue improvement over conventional cast $+1120 \mathrm{C}(2050 \mathrm{~F})$ HIP material. The wrought material still offered a 3-5X improvement over the cast MX Alloy 718.

\section{FUTURE WORK}

In order to reduce the data scatter, efforts have already been initiated to eliminate or reduce the presence of Laves' phase in MX cast Alloy 718 .

\section{ACKNOWLEDGEMENTS}

W. Freeman, J. VanderSluis, F. Norris, J. Lane, J. Brinegar, J. Vresics, L. DePatto, S. Mussman, and G. Cole contributed to the technical direction of the program. Metallography by D. Bakos and graphics by M. Stone were also invaluable.

\section{REFERENCES}

1. J. R. Brinegar, K. R. Chamberlain, J. J. Vresics and W. J. DePue, United States Patent "A Method of Forming a Fine-Grained Equiaxed Casting", Patent Number Pending.

2. H. L. Eiselstein, "Metallurgy of a Columbium-Hardened Nickel-ChromiumIron Alloy", STP 369, (1965) p62.

3. G. K. Bouse, Application of a Modified Phase Diagram to the Production of Cast Alloy 718 Components, this book.

4. R. V. Miner, "Fatigue" Superalloys II, Edited by Sims, Stoloff and Hagel, Published by Wiley (1986), p263.

Readers are invited to contact the authors for actual mechanical test values or enlarged graphs presented in this paper. 